\title{
Why portal hypertensive varices bleed and bleed: a hypothesis
}

\author{
P A McCormick, S A Jenkins, N McIntyre, A K Burroughs
}

\begin{abstract}
Continued bleeding or early rebleeding is associated with a poor prognosis in patients with variceal haemorrhage. It is not clear why bleeding stops in some patients and continues or restarts in others. It is suggested that secondary haemodynamic changes in the splanchnic circulation after a bleed may contribute to the risk of further bleeding. These changes include the effects of hypotension on portocollateral resistance, the effects of blood in the gut on splanchnic blood flow, and the effects of blood volume expansion on portal venous pressure during resuscitation. These factors, working in concert, cause a secondary rise in portal venous pressure, which may precipitate further bleeding. Treatment aimed at preventing these secondary haemodynamic changes may be beneficial. It is probable that somatostatin and octreotide could act in this way, which may explain their therapeutic efficacy.

(Gut 1995; 36: 100-103)
\end{abstract}

Keywords: variceal haemorrhage, splanchnic blood flow.

Bleeding from oesophageal varices is a common cause of death in patients with cirrhosis and portal hypertension. ${ }^{1}$ Treatment is aimed at stopping the bleeding and preventing rebleeding. Early rebleeding occurs more frequently from varices than from peptic ulcer disease (about $60 \% \quad v \quad 20 \%$ ) and usually occurs in the hours and days immediately after the initial bleed. ${ }^{2-4}$ Both bleeding that continues despite adequate treatment, and early rebleeding, are associated with a poor prognosis. ${ }^{23}$ Rebleeding and death are more common in patients with severely decompensated liver disease, alcoholic liver disease, and thrombocytopenia. The factors that sustain bleeding and that cause early rebleeding in individual patients are not well understood. ${ }^{5}$ Data are accumulating that leads us to suggest that changes in splanchnic blood flow after an initial bleed may contribute to the risk of further variceal bleeding. Treatment aimed at preventing or reversing these secondary haemodynamic changes may lead to better control of bleeding and improved prognosis.

Correspondence to: Dr P A McCormick University Department of Medicine, Rowland Hill Street, Hampstead, London NW3 2QG.

Accepted for publication 21 April 1994
Risk factors for rebleeding and death in variceal haemorrhage

There are now a large number of prospective studies looking at patients with portal hypertension and a number of risk factors for bleeding, rebleeding, and death have been identified. The most important risk factor is the severity of the underlying liver disease. It has been shown repeatedly that patients with decompensated liver disease bleed more often and have a worse prognosis than patients with compensated liver disease. ${ }^{56}$ Deterioration of liver function in hospital as a consequence of bleeding may be a further risk factor. It is possible that expeditious treatment to stop bleeding may favourably influence prognosis. ${ }^{7}$ In cirrhotic patients the prognosis is also worse in the presence of concomitant alcoholic hepatitis, hepatocellular carcinoma or portal venous thrombosis. ${ }^{8-10}$ The importance of liver function is underlined by the fact that prognosis is generally much better in patients without significant liver impairment, such as portal venous thrombosis or idiopathic portal hypertension. ${ }^{11} 12$

Although the degree of liver dysfunction is of over-riding importance in determining prognosis it is not clear why bleeding occurs unpredictably in individual patients. Other factors, in addition to liver function must be involved. Bleeding is more common in patients with large varices and in patients with greater curve fundal varices. ${ }^{513}$ In a few patients bleeding is precipitated by bacterial infection or by non-steroidal anti-inflammatory drug ingestion but most have no obvious immediate precipitant. We and others have noted a significant diurnal rhythm in the manifestation of variceal bleeding. ${ }^{14} 15$ In our unit we noted two peaks, one at 0800 and 2000. This pattern was not modified by age, sex, severity of liver disease or seasonal variation. ${ }^{14}$ The reason for this periodicity is unknown but may be related to circadian rhythms in the activity of the coagulation system. Such rhythms have been detected in normal subjects and patients with vascular disease but have not been systematically studied in cirrhotic patients. ${ }^{16}$ The time dependence of bleeding may also be related to diurnal variations in portal venous pressure, which have been detected in patients with portal hypertension. ${ }^{17}$

Once bleeding occurs a number of factors have been identified that increase the risk of early rebleeding. These include bleeding from gastric as compared with oesophageal varices, thrombocytopenia, encephalopathy, a diagnosis of alcoholic cirrhosis, large varices or active bleeding at the time of diagnostic endoscopy. 51318 These factors are all important but give comparatively little insight into the pathophysiology of 
rebleeding and do not readily explain why rebleeding should occur in an individual patient.

\section{Studies in humans during variceal haemorrhage}

Although it is difficult to investigate splanchnic haemodynamics in patients who are actively bleeding a number of studies have been done. These suggest that portal venous pressure is increased around the time of a bleed and that patients with higher portal venous pressure have a worse prognosis. Pomier-Layragues et al found that portal venous pressure was significantly higher immediately after a variceal bleed than when measured again 10 days and six months later. ${ }^{19}$ Vinel et al measured portal venous pressure in 72 patients with alcoholic cirrhosis within 48 hours of admission with variceal bleeding and found that higher portal venous pressure was associated with increased short term mortality. ${ }^{20}$ Patients who died within two weeks had a mean (SD) portal venous pressure of $25.6(8.4) \mathrm{mm} \mathrm{Hg}$ compared with $19.0(7 \cdot 6) \mathrm{mm} \mathrm{Hg}$ in survivors $(p<0.01)$. Similar results were reported by Ready et al who monitored portal venous pressure continuously and found that higher pressures on day 1 and 2 after admission were associated with both early rebleeding and a worse prognosis mean (SEM) $(20$ (1) $\mathrm{mm} \mathrm{Hg}$ in rebleeders $v 16$ (1) $\mathrm{mm} \mathrm{Hg}$ in nonrebleeders: $p<0.01) .21$ In addition they noted that rebleeding was usually preceded by a further increase in portal venous pressure. In one study continuous measurement of intravariceal pressure was performed in six patients during active bleeding. The mean (SEM) pressure was initially low (3.6 (1.1) $\mathrm{mm} \mathrm{Hg}$ ) but rose progressively to a peak at about six hours $(20.1(0.6) \mathrm{mm} \mathrm{Hg})$ before declining to a lower stable value $(14 \cdot 8(2 \cdot 1)$ $\mathrm{mm} \mathrm{Hg}){ }^{22}$ In another study variceal pressure was measured in 30 patients during bleeding and was found to be significantly higher than when measured again three or 10 days later. ${ }^{23}$ Taken together these studies suggest that portal venous pressure is raised around the
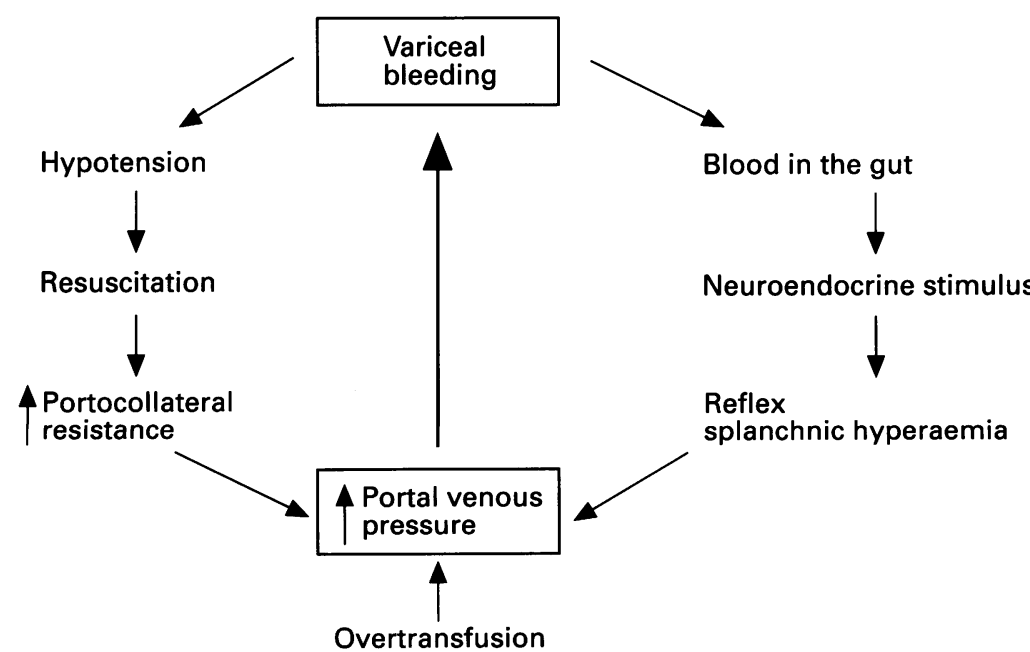

Changes in the splanchnic circulation that may occur after a variceal bleed in patients with portal hypertension. The resultant secondary rise in portal venous pressure may sustain active bleeding or precipitate further bleeding. time of a variceal bleed and that the height of the portal venous pressure during a bleeding episode is an important risk factor for rebleeding and mortality.

The rationale for using drugs such as vasopressin and glypressin for active bleeding is based on the assumption that the height of the portal venous pressure is important in maintaining or precipitating variceal haemorrhage. But it is important to realise that portal venous pressure is a dynamic variable, which is determined by the combination of splanchnic blood inflow and the resistance to portal venous outflow, through both the liver and the collateral circulation. Thus portal venous pressure could be raised by increasing splanchnic blood flow or increasing portocollateral vascular resistance, or both.

\section{Splanchnic circulatory changes after} bleeding in portal hypertensive animals Experiments in animal models of portal hypertension have suggested that the splanchnic circulation may respond to hypovolaemia and resuscitation in an unusual way. ${ }^{24} 25$ During haemorrhage the expected fall of about $30 \%$ in portal venous pressure occurred, but after blood volume restitution portal venous pressure rose significantly to values about $20 \%$ higher than baseline pressures. This 'overshoot' occurred despite unchanged splanchnic blood inflow and was attributed to increased resistance in the portocollateral vessels. The investigators speculated that release of vasoactive mediators during the period of hypovolaemia may be responsible. It is not known if similar changes also occur in humans.

\section{Factors that may increase splanchnic blood flow after variceal haemorrhage in humans}

There are at least two factors which, theoretically, may increase splanchnic blood inflow and thus portal venous pressure after a bleed: (a) over transfusion and (b) the effects of blood in the gut on splanchnic blood flow.

Overtransfusion - blood volume expansion increases portal venous pressure in humans with cirrhosis. ${ }^{26} 27$ Classic surgical practice and training cautions against overtransfusing patients with gastrointestinal bleeds because of the danger of precipitating further bleeding and there are anecdotal reports of variceal bleeding occurring after blood volume expansion. ${ }^{26} 28$

The effects of blood in the gut on splanchnic blood flow - blood contains large amounts of protein and many have similar effects on the gut as a protein containing liquid meal. Protein and non-protein containing meals are known to increase splanchnic blood flow and portal venous pressure in patients with cirrhosis and portal hypertension. ${ }^{29-31}$ It would seem logical to expect that blood in the gut may have similar effects, which may become manifest when the patient is resuscitated and the initial period of hypotension is over. Blood in the gut may then cause reflex splanchnic hyperaemia and cause a secondary increase in portal 
venous pressure. The mechanisms underlying postprandial hyperaemia are not well understood but probably entail the intestinal nerves and the release of gastrointestinal peptides that may act in an endocrine or a paracrine fashion. 3233

\section{Hypothesis}

We think that the events shown in the Figure may occur, sequentially or simultaneously, after a variceal bleed and adequate resuscitation. After resuscitation there may be an increase in resistance to portal blood flow and a consequent increase in portal venous pressure. The presence of blood in the gut may then cause reflex splanchnic hyperaemia with increased blood flow into the portal venous system. The combination of increased blood flow and increased resistance would result in a further rise in portal venous pressure, which may precipitate further variceal bleeding. If the patient is overtransfused these changes may be magnified. A vicious cycle may be established where bleeding, hypovolaemia, and subsequent resuscitation increase the chances of further bleeding.

\section{Therapeutic implications}

To date emergency pharmacological treatment of variceal bleeding has focused primarily on lowering portal venous pressure. ${ }^{34}$ If our hypothesis is correct, treatment aimed at preventing or ameliorating the secondary changes in splanchnic haemodynamics may also be useful. One therapeutic option would be to remove the blood from the gastrointestinal tract as quickly as possible to prevent secondary splanchnic hyperaemia. In this context it is interesting that a French trial reported that whole gut irrigation with isotonic mannitol reduced blood transfusion requirements and death rates in cirrhotic patients with gastrointestinal bleeding. ${ }^{35}$

An alternative approach would be to suppress the secondary haemodynamic changes by pharmacological means. We believe that somatostatin and its long acting analogue octreotide may act in this way. There is a growing body of evidence to suggest that both drugs are effective in the emergency treatment of bleeding varices. ${ }^{36-40}$ Both somatostatin and octreotide seem to have little direct effect on the splanchnic arteries but are believed to work by inhibiting the release of endogenous vasodilator substances, such as glucagon. ${ }^{41-45}$ Using duplex Doppler ultrasound, octreotide has been shown to prevent or inhibit meal related splanchnic hyperaemia in normal subjects. ${ }^{4647}$ In cirrhotic patients with portal hypertension octreotide prevented postprandial splanchnic hyperaemia and the associated increase in portal venous pressure. ${ }^{48}{ }^{49}$ In portal hypertensive rats octreotide given after bleeding reduced collateral blood flow and prevented the increase in collateral blood flow after resuscitation. ${ }^{50} \mathrm{We}$ suggest that somatostatin and its analogues may also act to prevent the release of vasoactive peptides and the associated splanchnic hyperaemia after a variceal bleed. As a consequence they may prevent further rises in portal venous pressure and thus reduce the risk of early rebleeding.

In conclusion, we suggest that changes in splanchnic haemodynamics after a variceal bleed in patients with portal hypertension may contribute to the high risk of continued bleeding and early rebleeding. The effects of hypotension, resuscitation, and blood in the gut may combine to increase splanchnic blood flow and portal venous pressure after a bleed. To date, emergency pharmacological treatment of variceal bleeding has concentrated on reducing portal venous pressure. We suggest that treatment aimed at preventing rises in portal venous pressure after a bleed may also be an effective strategy.

1 Burroughs AK, McCormick PA. Natural history and prognosis of variceal bleeding. Baillieres Clin Gastroenterol 1992; 6: 437-50

2 Graham DY, Smith JL. The course of patients after variceal hemorrhage. Gastroenterology 1981; 80: 800-9.

3 Burroughs AK, D'Heygere F, Phillips A, McIntyre N. Predictive model for early failure to control variceal bleeding [Abstract]. Hepatology 1986; 6: 1153.

4 Northfield TC. Factors predisposing to recurrent hemorrhage after acute gastrointestinal bleeding. BMF 1971;1:26-8.

5 De Franchis $R$, Primignani $M$. Why do varices bleed? Gastroenterol Clin North Am 1992; 21: 85-101.

6 Burroughs AK, Mezzanotte G, Phillips A, McCormick PA, McIntyre N. Cirrhotics with variceal hemorrhage: the importance of the time interval between admission and the start of analysis for survival and rebleeding rates. Hepatology 1989; 9: 801-7.

7 McCormick PA, Kaye GL, Greenslade L, et al. Esophageal staple transection as a salvage procedure after failure of acute injection sclerotherapy. Hepatology $1992 ; 15: 403-6$.

8 Sarfeh IJ. Portal vein thrombosis associated with cirrhosis. Arch Surg 1979; 114: 902-5.

9 Lo GH, Lin CY, Lai KH, et al. Endoscopic injection sclerotherapy versus conservative treatment for patients with unresectable hepatocellular carcinoma and bleeding with unresectable hepatocellular carcinoma and bleeding

10 Orrego $\mathrm{H}$, Blake JE, Blendis LM, Medline A. Prognosis of alcoholic cirrhosis in the presence and absence of alcoholic hepatitis. Gastroenterology 1987; 92: 208-14.

11 Webb LJ, Sherlock S. The aetiology, presentation and natural history of extra-hepatic portal venous obstruction. $Q \mathcal{F}$ Med 1979; 48: 627-39.

12 Okuda K, Kono K, Ohnishi K, Kimura K, Omata M, Koen $\mathrm{H}$, et al. Clinical study of eighty-six cases of idiopathic portal hypertension and comparison with cirrhosis with splenomegaly. Gastroenterology 1984; 86: 600-10.

13 Sarin SK, Lahoti D, Saxena SP,. Murthy N, Makwana EK. Prevalence, classification and natural history of gastric varices: a long-term follow-up study in 568 portal hypervarices: a long-term follow-up study in 568 portal
tension patients. Hepatology 1992; 16: 1343-9.

14 Merican I, Sprengers D, McCormick PA, Minoli G, McIntyre N, Burroughs AK. Diurnal pattern of variceal bleeding in cirrhotic patients. $\mathcal{F}$ Hepatol 1993; 19: 15-22.

15 Casale R, Pasqualetti P. Circadian periodicity of the time of onset of acute upper gastrointestinal bleeding episodes. II United European Gastroenterology Week Abstract Book. 1993: A266.

16 Petralito A, Mangiafico RA, Gibiino S, Cuffari MA, Miano MF, Fiore CE. Daily modifications of plasma fibrinogen, platelets aggregation, Howell's time, PTT, TT and antithrombin III in normal subjects and in patients with vascular disease. Chronobiologia 1982; 9: 195-201.

17 Garcia-Pagan JC, Feu F, Castells A, et al. Circadian variations of portal pressure and variceal haemorrhage in patients with cirrhosis. Hepatology 1994; 19: 595-601

18 Cardin F, Gori G, McCormick PA, Wannamethee G, McIntyre $\mathrm{N}$, Burroughs $\mathrm{AK}$. A predictive model for very early rebleeding from varices. Gut 1990; 31: A1204.

19 Pomier-Layragues G, Villenueve J, Willems B, Huet PM, Marleu D. Systemic and hepatic hemodynamics after variceal hemorrhage: effects of propranolol and placebo. Gastroenterology 1987; 93: 1218-24.

20 Vinel JP, Cassigneul J, Levade M, Boight JJ, Pascal JP. Assessment of short-term prognosis after variceal bleeding in patients with alcoholic cirrhosis by early measurement of portohepatic gradient. Hepatology 1986; 6: 116-7.

21 Ready JB, Robertson AD, Goff JS, Rector WG. Assessment of the risk of bleeding from esophageal varices by conof the risk of bleeding from esophageal varices by con-
tinuous monitoring of portal pressure. Gastroenterology tinuous monitoring

22 Staritz M, Rambos A, Alkier R, Grosse A, Meyer zum Staritz M, Rambos A, Alkier R, Grosse A, Meyer zum
Buschenfelde KH. Pressure profile in human esophageal varices during and after variceal bleeding obtained with a novel technique for continuous pressure monitoring. Gastroenterology 1992; 102: A893. 
23 Ruiz Del Arbol I, Martin de Argila C, Vazquez M, Arocena C, Monescillo A, Garcia Plaza A, et al. Endoscopic measurement of variceal pressure (VP) during haemorrhage from esophageal varices (HEV). Hepatology 1992; 16: $81 \mathrm{~A}$.

24 Kravetz D, Sikuler E, Groszmann RJ. Splanchnic and systemic hemodynamics in portal hypertensive rats during hemorrhage and blood volume restitution. Gastroenterology 1986; 90: 1232-40.

25 Kravetz D, Bosch J, Arderiu M, Pizcueta MP, Rodes J. Hemodynamic effects of blood volume restitution following a haemorrhage in rats with portal hypertension due to ing a haemorrhage in rats with portal hypertension due to cirrhosis of the liver: influence of the extent
systemic shunting. Hepatology 1989; 9: 808-14.

26 Boyer JL, Chatterjee C, Iber FL, Basu AK. Effect of plasma volume expansion on portal hypertension. $N$ Engl $\mathcal{F}$ Med 1966; 275: 750-5

27 Zimmon DS, Kessler RE. The portal pressure-blood volume relationship in cirrhosis. Gut 1974; 15: 99-101.

28 Markey W, Payne JA, Straus A. Hemorrhage from esophageal varices after placement of the LeVeen shunt. Gastroenterology 1979; 77: 341-3.

29 Castleman L, Brandt JL, Ruskin H. The effect of oral feeding of meat and glucose on hepatic vein wedge pressure in normal and cirrhotic subjects. F Lab Clin Med 1958; 51: 897-903.

30 Lee SS, Hadengue A, Moreau R, Sayegh R, Hillon P, Levrec D. Postprandial hemodynamic responses in patients with cirrhosis. Hepatology 1988; 8: 647-51.

31 McCormick PA, Dick R, Graffeo M, Wagstaff D, Madden A, McIntyre N, et al. The effect of non-protein liquid meals on the hepatic venous pressure gradient in cirrhotic patients. F Hepatol 1990; 11: 221-5.

32 Premen AJ, Kvietys PR, Granger DN. Postprandial regulation of intestinal blood flow: role of gastrointestinal hortion of intestinal blood flow: role of gastroir

33 Rozsa Z, Jacobson ED. Capsaicin-sensitive nerves are involved in bile-oleate-induced intestinal hyperemia. Am f Physiol 1989; 256: G476-81.

34 Garden OJ, Carter DC. Balloon tamponade and vasoactive drugs in the control of acute variceal haemorrhage. Baillieres Clin Gastroenterol 1992; 6: 451-63.

35 Hecketsweiler P, Colin R, Ouvry D, Galmiche JP, Paillot B, Geffroy Y. Le lavage digestif par une solution de mannitol au cours des hemorragies digestives du cirrhotique. Resultats d'une etude controlee. Gastroenterol Clin Biol 1978; 2: 145-52.

36 Jenkins SA Baxter JN, Corbett WA, Devitt P, Ware J, Shields $R$. A prospective randomised controlled clinical trial comparing somatostatin and vasopressin in controlling acute variceal haemorrhage. $B M 7$ 1985; 290: 275-8.

37 Burroughs AK, McCormick PA, Hughes MD, et al. Randomized double-blind placebo controlled trial of somatostatin for variceal bleeding. Gastroenterology 1990; 99: 1388-95.

38 Avgerinos A, Klonis C, Rekoumnis G, Gouma P, Papadimitriou N, Raptis S. A prospective randomised trial comparing somatostatin, balloon tamponade, and the combination of both methods in the management of acute variceal haemorrhage. F Hepatol 1991; 13: 78-83. 39 Silvain C, Carpentier S, Satereau D, et al. Terlipressin plus transdermal nitroglycerin vs octreotide in the control of acute bleeding from esophageal varices: a

40 Sung JJ, Chung SCS, Lai CW, et al. Octreotide infusion or emergency sclerotherapy for variceal haemorrhage. Lancet 1993; 342: 637-41

41 Sieber CC, Mosca PG, Groszmann RJ. Effect of somatostatin on mesenteric vascular resistance in normal and portal hypertensive rats. Am $\mathcal{f}$ Physiol 1992; 262: G274-7.

42 Adrian TE, Barnes AJ, Long RG, et al. The effect of somatostatin analogs on secretion of growth, pancreatic, and gastrointestinal hormones in man. 7 Clin Endocrinol Metab 1981; 53: 675-81.

43 McCormick PA, Dick R, Siringo S, et al. Octreotide reduces azygos blood flow in cirrhotic patients with portal hypertension. Eur $\mathcal{F}$ Gastroenterol Hepatol 1990; 2: 489-92.

44 McCormick PA, Seifalian A, Stansby G, McGann G, Collins P, Chin J, et al. Superior mesenteric artery blood flow in man measured with intra-arterial Doppler catheters: effect of octreotide. $\mathcal{F}$ Hepatol 1993; 17: 20-7.

45 Malesci A, Basilico M, Tacconi M, Lorenzano E, Valentini A, Primignani $M$, et al. Effect of 15-day treatment with octreotide on glucagon levels in patients with cirrhosis of the liver. Gastroenterology 1992; 102: A847.

46 Kooner JS, Peart WS, Matthias CJ. The peptide release inhibitor, octreotide (SMS 201-995) prevents the haemodynamic changes following food ingestion in normal dynamic changes following food ingestion in nom subjects. $Q f$ Exp Physiol 1989; 74: 569-72.

47 Cooper AM, Braadvedt GD, Qamar MI, et al. Fasting and post-prandial splanchnic blood flow is reduced by a somatostatin analogue (octreotide) in man. Clin Sci 1991; 81: 169-75.

48 Buonamico P, Jensen JE, Sabba C, et al. Octreotide blunts portal post-prandial hyperemia in cirrhotic patients. Hepatology 1991; 14: 96A.

49 McCormick PA, Biagini MR, Dick R, et al. Octreotide inhibits the meal-induced increases in the portal venous pressure of cirthotic patients with portal hypertension: a double-blind, placebo-controlled study. Hepatology 1992; 16: $1180-6$.

50 Yates J, Nott DM, Kynaston $\mathrm{H}$, et al. Hypovolaemia and reperfusion in portal hypertension: effects of somatostatin, octreotide and vasopressin [Abstract]. HPB Surg 1993; 6 (suppl): 150 . 